\title{
Study on Compressive Properties of Recycling PETs and CANs for Designing a Smart Waste Management Compactor
}

\author{
BOGDAN FELICIAN ABAZA, PAULINA SPANU*, BOGDAN ALEXANDRU JUGRAVU, \\ DRAGOS ALEXANDRU APOSTOL \\ University Politehnica of Bucharest, 313 Splaiul Independentei, 060042, Bucharest, Romania
}

\begin{abstract}
Recycling is a key process in any sustainable development strategy. This paper proposes solutions for the increasing waste collection rates by developing an educational model for developing innovative waste management solutions. The focus in this paper will be on making the correlation between experimental studies on compressive properties of recycling waste and designing a smart waste management compactor. Based on previous achievements on developing an innovative compactor system with selective waste collection, actual experimental trials will be analysed for generating compression patterns for different types of common waste containers which will be used in the conceptual design process of a compactor, impacting concept definition of all 3 subsystems: mechanical, electrical and software. A dedicated software module for compression parameters will be developed for importing experimental data trials and based on these to process and identify relevant compression parameters defining compression pattern for different common waste containers. These parameters will be used to assist the wok mode state machines for compacting wastes. This will improve compactor performance by optimization of compactor usage smart adaptability.
\end{abstract}

Keywords: recycling, compression, waste compactor, product development, Industry 4.0, LabVIEW

\section{Introduction}

Polyethylene terephthalate (PET) is $100 \%$ recyclable and the most recycled plastic packaging material in Europe [1]. PET packaging can be used as a raw material for the textile industry, automotive, construction, new packaging for food and non-food products, for obtaining other PETs, etc.

Much less energy is used to manufacture PET from recycled materials, the manufacturing cost is much lower, but it has the disadvantage that much more $\mathrm{CO}_{2}$ is released into the atmosphere.

In addition, they can be recycled several times until they change their properties and can no longer be recycled.

Although the incineration of PET waste is more attractive for reducing the volume of landfills and for recovering energy by burning, it is necessary to abandon these practices due to the negative effects on the atmosphere generated by gas combustion.

The paper aims to continue existing studies and developments in recent years at the level of master's programs focused on the development of innovative products that serve the need for recycling of household waste. Some of these product ideas have proposed innovative solutions to reduce the volume by compacting recyclable waste like PET and cans. This reduction in volume can lead to an increase in the amount of recyclable waste by accelerating the process of sorting and collecting them especially from domestic users.

This article continues the research and development process of designing an innovative compactor system with selective waste collection. One achievement was a software application for Smart Management Application has been developed [2].

*email: email: pauspa16@yahoo.com 


\section{Materials and methods}

\subsubsection{Waste management system architecture}

Concept designing process was performed on a different development approach for the whole waste management ecosystem, based on Industry 4.0 concepts and principles, where the is a vertical integration with a hierarchical level component. It is about the integration of all IT system components (hardware and software) at various hierarchical levels into one comprehensive solution. In our case these hierarchical levels are respectively the field level, the control level, the process line level, the operations level and the ecosystem planning level represented by the Waste Management Ecosystem [2]. The system architecture can also be seen as an interaction between 3 subsystems: mechanical, electrical and software according with Figure 1.

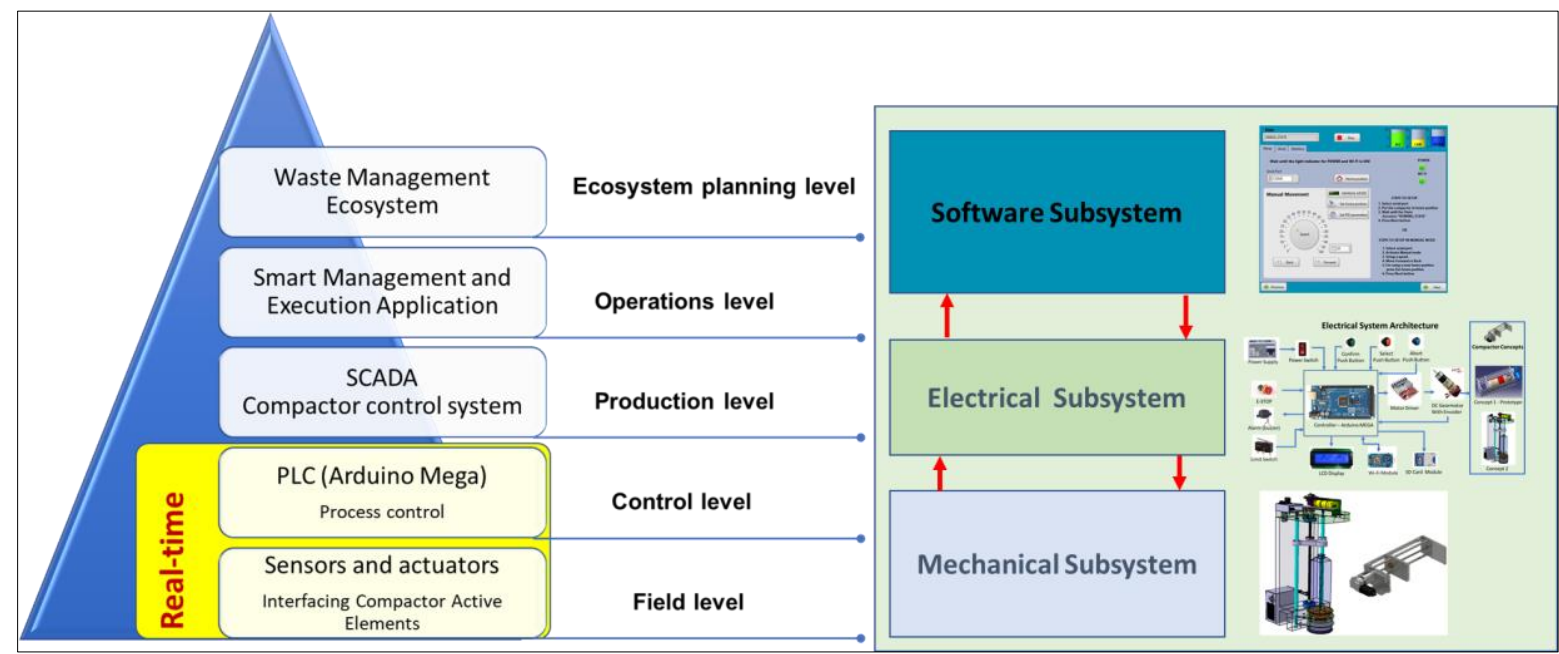

Figure 1. Waste Management System Architecture

Industry 4.0 Design Principles (Figure 2) [3,4] were applied in designing each subsystem from our system based on similar levels like those from an automation pyramid:

1. Level one: sensors and actuators - connecting what should be connected at the level of compactor physical active parts representing the 'things and device' layer)

2. Level two: systems and internal services - monitor and manage in real time process at the level of the controller

3. Level thee: connectivity - connect for new applications and capabilities of the compactor

4. Level four: new services and ecosystems - transformation from the Waste Management Ecosystem.

\begin{tabular}{|c|c|}
\hline & $\begin{array}{l}\text { 14.0 Design Principles } \\
\text { six so-called design principles }\end{array}$ \\
\hline 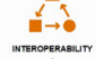 & DP1: Interoperability, interconnection, connectivity \\
\hline$\sqrt{t, b}$ & $\begin{array}{l}\text { DP2: Information transparency, virtualization and virtual } \\
\text { entities }\end{array}$ \\
\hline 我。 & DP3: Decentralization, autonomous decisions and autonomy \\
\hline$[0]$ & DP4: Real-time capability: visibility SCM on demand \\
\hline 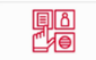 & DP5: Technical assistance and service orientation \\
\hline Sis & DP6: Modularity \\
\hline
\end{tabular}

Figure 2. Example of a figure caption 


\subsection{Mechanical subsystem architecture}

Mechanical Subsystem Architecture was based on several student concepts. Most of them use a screw nut mechanism for the compression subsystem of the waste. The screw is driven by an DC electric motor. Each concept proposes different solutions for compressing active parts taking in account some preliminary experimental trials. Two of them are presented in Figure 3 [2].

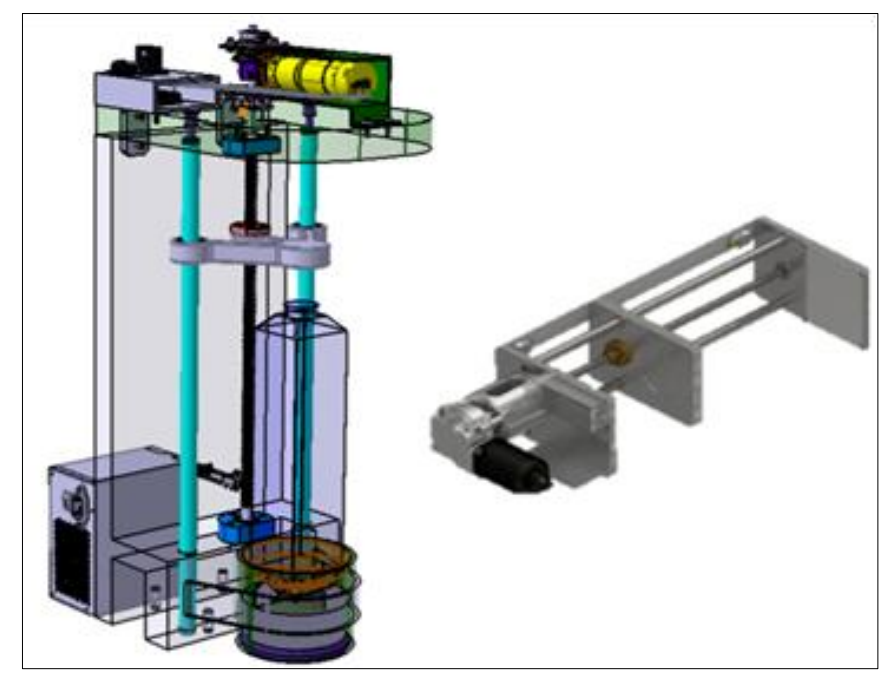

Figure 3. Example of a figure caption

This paper will focus on an extensive set of experimental trials for building the experimental study on compressive properties of waste (pets and cans). This study could serve in 2 main ways:

- In further concept generation of different solutions for compressing active parts from the mechanical and electrical subsystems.

- In software optimization of actual concepts prototypes by integration of a new module in the existing software application, module which will allow configuring compressing force and deformation range assuring a better control and adjustments of pet/can deformation parameters based on compression patterns determined on experimental results analysis and data processing.

\subsection{Electrical subsystem architecture}

The prototype's electrical architecture respects automation pyramid covers the most relevant components from the first level 1: sensors and actuators and level 2 PLC from level 2. This architecture is detaild in Figure 4 [2].

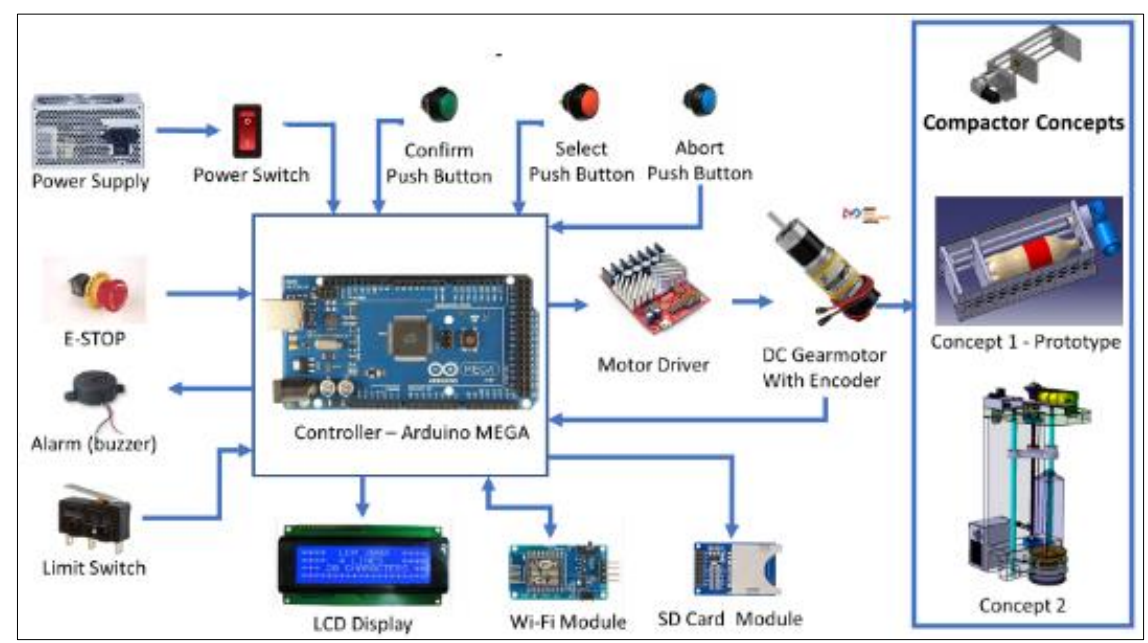

Figure 4. Example of a figure caption 


\subsection{Software subsystem architecture}

Software subsystem was designed based on a State Machines programming architecture. It was developed in LabVIEW, a system engineering software suitable for applications that allows event-driven state machines where dynamic flow to states depending on values from previous states or user/ecosystem inputs. Based on functional analysis and previous electrical architecture there were defined 8 states machines for the real time controller. Two of work state machines are presented in Figure 5 [2]. In Figure 5a PET_STATE is state machine, belonging to group of work state machines, for compressing a PET when user can be assisted step by step during the cycle of the process: starting with choose the waste, choose the volume, open the door, place the waste inside, close the door, start compacting until the waste is compacted and automatically drop to the right bin, and getting ready for a new cycle. In Figure $5 b$ CAN_STATE is state machine, belonging to group of work state machines, for compressing a CAN and it is similar with the PET one but customized for compressing a can.

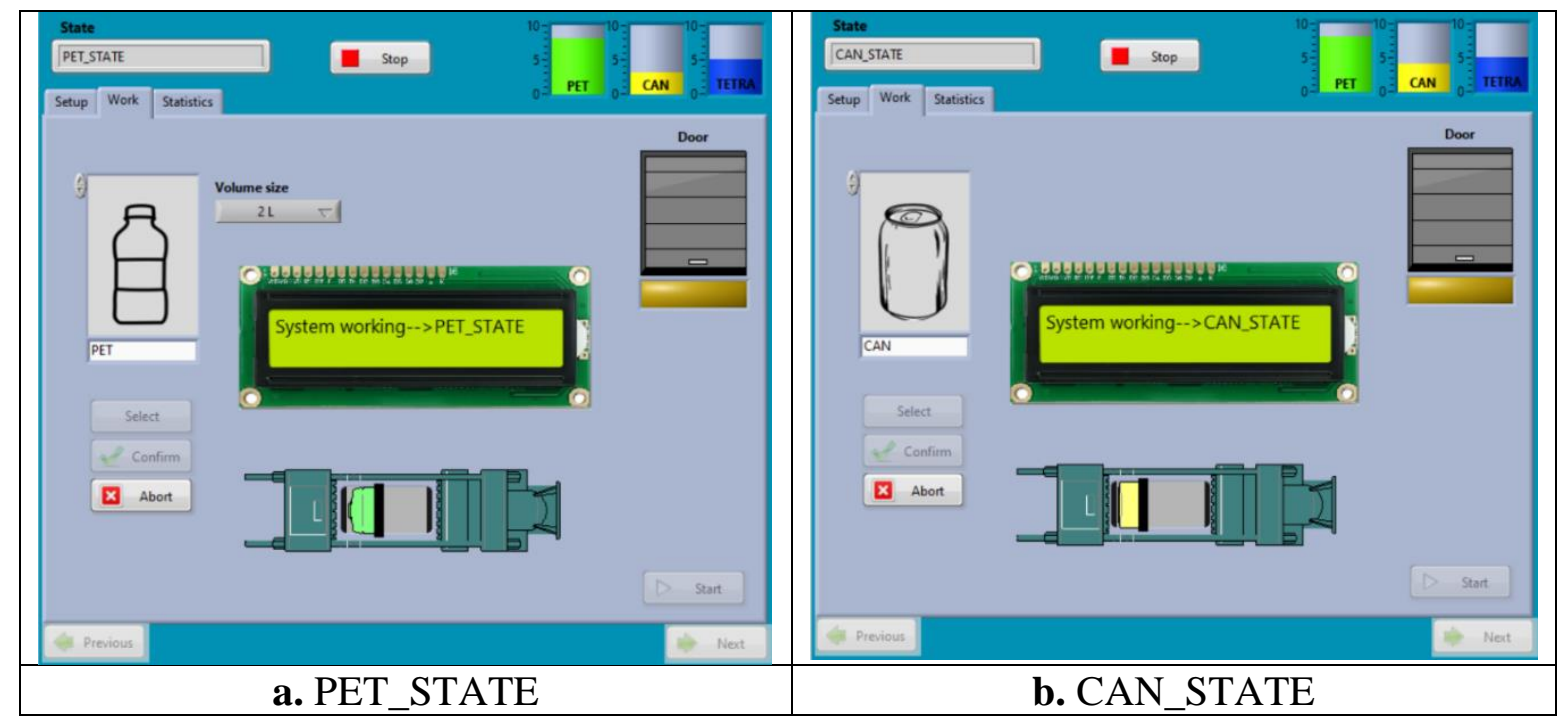

Figure 5. Work State machines

DEBUG_STATE is the setup state machine. In Figure 6a it is presented the initial interface with initial functionalities. In this paper it will be presented a new version of DEBUG_STATE state machine for which it will be added new functionalities for improving optimization of the working parameters for compacting of wastes. Those functionalities will be developed based on additional input data, collected from the experimental trials, which can be loaded into the software (Figure 6b).

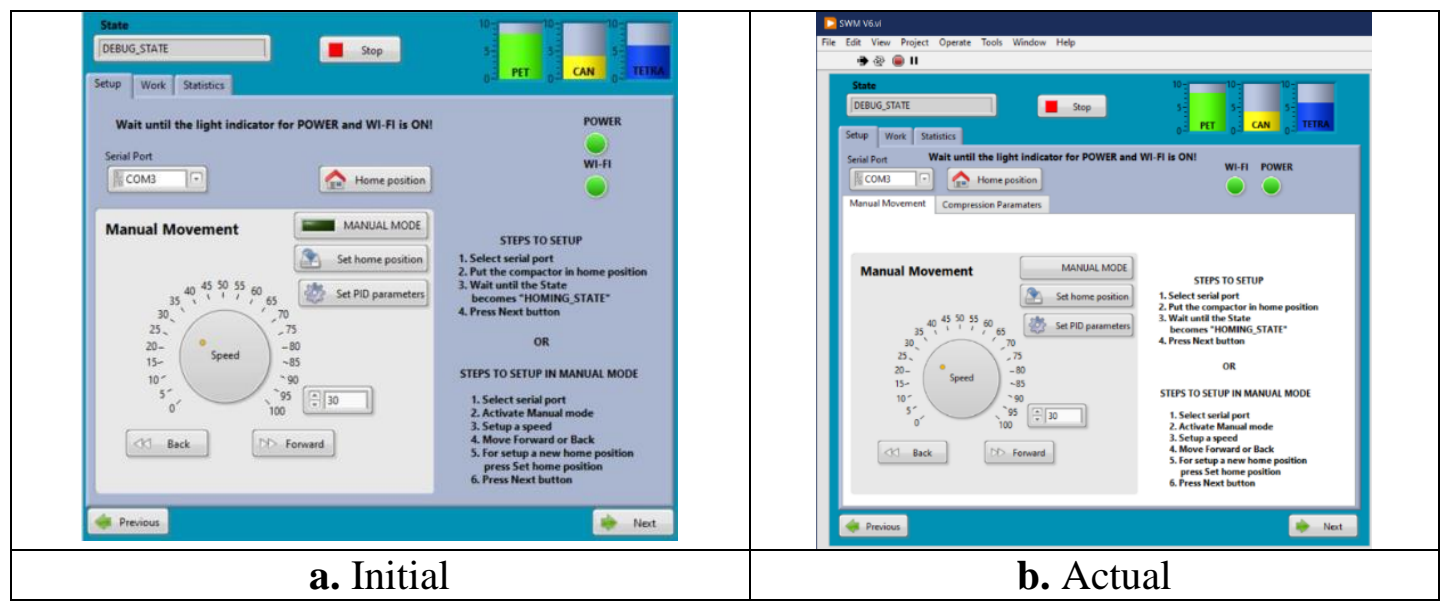

Figure 6. DEBUG_STATE State machine 


\section{Results and discussions}

\subsection{Experimental trials}

Initially, preliminary experimental trials to determine the forces required to compress the waste were made using a variety of types of waste: cans, PET bottles, Tetra Pack, of different heights and thicknesses. It was used a Zwick/Roell ProLine table-top testing machine [2].

After the preliminary experimental trials, it was designing a first prototype based on a screw nut mechanism for the compression subsystem of the waste (Figure 7).

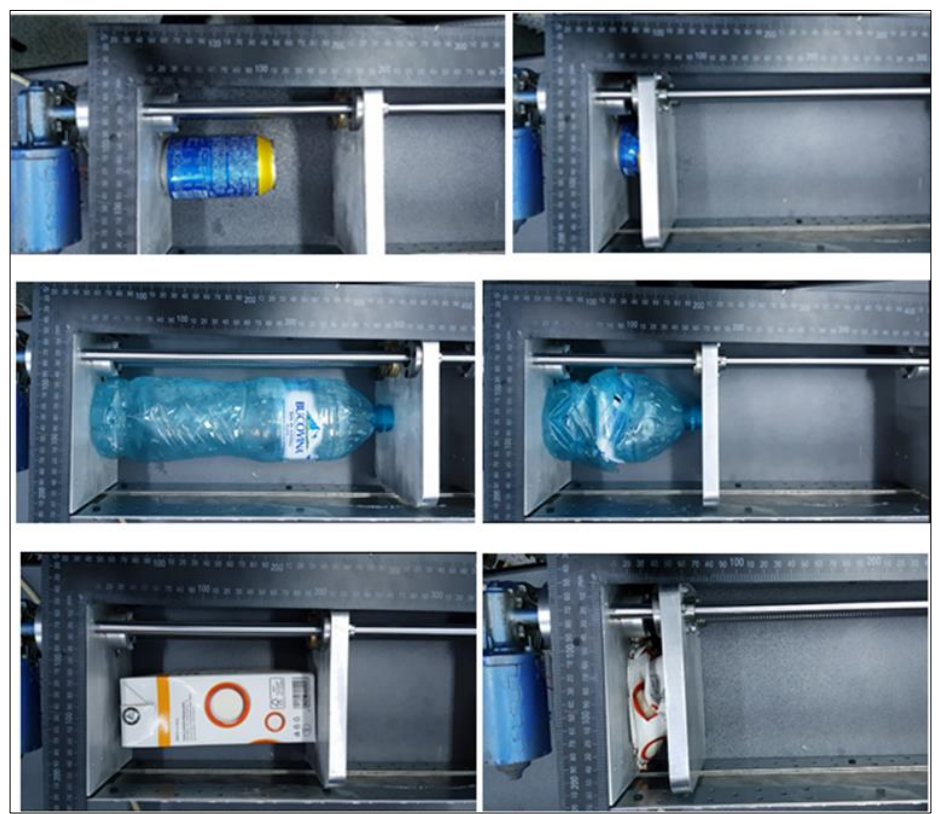

Figure 7. Example of a figure caption

After a set of tests, most of the functionalities and performance were confirmed but it was proved that for continuing design optimization of mechanical subsystem with the compressing active parts and for software subsystem optimization, a deeper study on Compressive Properties of pets and cans is needed [5].

It was used the same testing machine: Zwick/Roell ProLine (Figure 8).

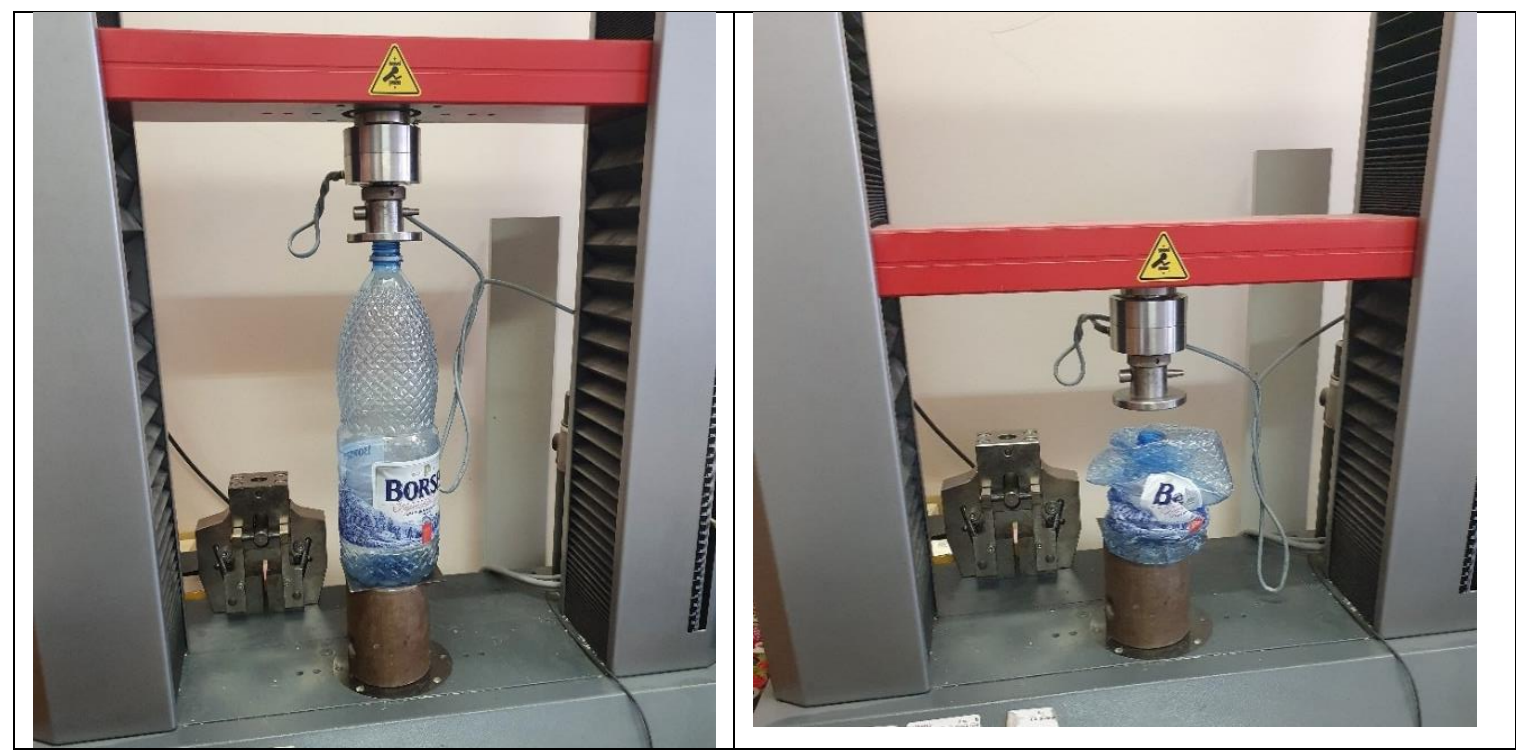

Figure 8. Zwick/Roell ProLine testing machine 
A wider range of popular plastic pets and cans were selected for the new set of experimental trials. Selection was made taking in account inputs related to: material, volume, plastic texture, shape and mass $[6,7]$.

A selection of the most relevant of pet and can specimens subjected to the compression test are presented in Table 1.

Table 1. Selection of relevant of pet and can recipients

\begin{tabular}{|c|c|c|c|c|}
\hline \multirow{2}{*}{ Trial } & \multirow{2}{*}{$\begin{array}{l}\text { Waste } \\
\text { Type }\end{array}$} & \multirow{2}{*}{ Material } & Volume & $\mathbf{H}$ \\
\hline & & & {$[\mathbf{L}]$} & {$[\mathrm{mm}]$} \\
\hline PET1 Bucovina & Bottle & PET & 2 & 340 \\
\hline PET2 Bucovina & Bottle & PET & 2 & 340 \\
\hline PET3 Tusnad & Bottle & PET & 2 & 355 \\
\hline PET4 Tusnad & Bottle & PET & 2 & 355 \\
\hline PET5 Borsec & Bottle & PET & 2 & 333 \\
\hline PET6 Cola & Bottle & PET & 1.25 & 312 \\
\hline PET7 Bucovina & Bottle & PET & 0.5 & 221 \\
\hline PET8 Dorna & Bottle & PET & 0.5 & 212 \\
\hline PET9 Dorna & Bottle & PET & 0.5 & 212 \\
\hline PET10 Borsec & Bottle & PET & 2 & 330 \\
\hline PET11 Cola & Can & $\mathrm{AL}$ & 0.33 & 146 \\
\hline
\end{tabular}

Based on experience from testing the prototype, it was design the test trials where for each waste (pet or can) the compression trial starts from initial height $\mathrm{H}$ and, measuring force $\mathrm{F}[\mathrm{N}]$ and deformation $[\mathrm{mm}]$ it was ended when the final height Hc (resulted height after compression) arrived at 40mm. For each trial an experimental data file (*.TRA format) was generated by the testXpert testing software from Zwick/Roell equipment. The representative measured data fields were: Standard force, Standard travel, Tool separation, Test time, Time (Figure 9).

\begin{tabular}{|c|c|c|c|c|c|c|}
\hline 1 & Standard force & Standard travel & Absolute crosshead travel & Tool separation & Test time & Time \\
\hline 2 & $\mathrm{~N}$ & $\mathrm{~mm}$ & $\%$ & $\mathrm{~mm}$ & $\mathrm{~s}$ & $\mathrm{~s}$ \\
\hline 3043 & 443.684 & 298.12 & -74.7477 & 40.0007 & 30.45 & 40.47 \\
\hline 3044 & 442.512 & 298.12 & -74.7476 & 40.0006 & 30.46 & 40.48 \\
\hline 3045 & 441.363 & 298.12 & -74.7476 & 40.0005 & 30.47 & 40.49 \\
\hline 3046 & 440.246 & 298.12 & -74.7475 & 40.0003 & 30.48 & 40.5 \\
\hline 3047 & 439.16 & 298.12 & -74.7475 & 40.0003 & 30.49 & 40.51 \\
\hline 3048 & 438.098 & 298.12 & -74.7475 & 40.0003 & 30.5 & 40.52 \\
\hline 3049 & 437.067 & 298.121 & -74.7475 & 40.0002 & 30.51 & 40.53 \\
\hline 3050 & 436.059 & 298.121 & -74.7475 & 40.0001 & 30.52 & 40.54 \\
\hline 3051 & 435.086 & 298.121 & -74.7475 & 40.0001 & 30.53 & 40.55 \\
\hline
\end{tabular}

Figure 9. Extras from a TRA experimental data file

A set of 11 waste (pet and can) samples were tested for the compression. Analyzing experimental data, it was revealed 3 relevant stages specific to the compression of a waste (Table):

1. Initiation when it is elastic deformation, and it ends with a maximum F1max which indicates starting plastic deformation of the waste.

2. Development - when pet/can has plastic deformation, bottle or can has most significant deformation, the volume has most significant reduction and F2max is the maximum force during this stage

3. Ending - when pet/can become compacted and the force is increasing rapidly and F3max is the maximum force from this stage 
Table 2. Selection of relevant compression test results

\begin{tabular}{|c|c|c|c|c|c|c|c|c|c|c|}
\hline \multirow{2}{*}{ Trial } & Volume & H & D1 & F1max & D2 & F2max & D3 & F3max & Hc & $\begin{array}{c}\text { Compression } \\
\text { Ratio }\end{array}$ \\
\cline { 2 - 13 } & {$[\mathbf{L}]$} & {$[\mathrm{mm}]$} & {$[\mathrm{mm}]$} & {$[\mathrm{N}]$} & {$[\mathrm{mm}]$} & {$[\mathrm{N}]$} & {$[\mathrm{mm}]$} & {$[\mathrm{N}]$} & {$[\mathrm{mm}]$} & H/Hc \\
\hline PET1 Bucovina & 2 & 340 & 12 & 96 & 134 & 179 & 297 & 485 & 43 & 7.91 \\
\hline PET2 Bucovina & 2 & 340 & 11 & 75 & 137 & 181 & 298 & 497 & 42 & 8.10 \\
\hline PET3 Tusnad & 2 & 355 & 7 & 96 & 133 & 175 & 305 & 494 & 50 & 7.10 \\
\hline PET4 Tusnad & 2 & 355 & 8 & 95 & 142 & 173 & 299 & 503 & 56 & 6.34 \\
\hline PET5 Borsec & 2 & 333 & 3 & 53 & 159 & 120 & 293 & 621 & 40 & 8.33 \\
\hline PET6 Cola & 1.25 & 312 & 5 & 151 & 12 & 73 & 209 & 115 & 29 & 3.03 \\
\hline PET7 Bucovina & 0.5 & 221 & 8 & 27 & 69 & 43 & 180 & 196 & 41 & 5.39 \\
\hline PET8 Dorna & 0.5 & 212 & 7 & 42 & 96 & 65 & 169 & 228 & 43 & 4.93 \\
\hline PET9 Dorna & 0.5 & 212 & 7 & 49 & 93 & 70 & 172 & 233 & 40 & 5.30 \\
\hline PET10 Borsec & 2 & 330 & 5 & 99 & 163 & 169 & 290 & 620 & 40 & 8.25 \\
\hline PET11 Cola & 0.33 & 146 & 1 & 309 & 13 & 114 & 102 & 238 & 44 & 3.32 \\
\hline
\end{tabular}

These data confirmed a similar compression behaviour with the precedent trials and with the prototype compression cycle resulted from proto tests. During the deformation process there are 3 main forces thresholds to take in account: F1, F2 and F3 corresponding to: initiation, development and ending stages. It is relevant to identify the maximum of these for each stage and based on this variance from waste to waste to identify proper sets of values for force and deformation which can become input parameters for setting and optimization of the compactor compressing subsystem.

Figure 10 shows the forces - deformation for trial PET2, 2L volume and one of the biggest height $\mathrm{H}$ - 340mm. This is the case when compacting ratio of 8.1 indicating a significant volume reduction by compacting.

Compression Ratio $=\mathrm{H} / \mathrm{Hc}$ where $\mathrm{H}[\mathrm{mm}]$ is the initial height of the recipient and $\mathrm{Hc}$ is the resulted height after compression.

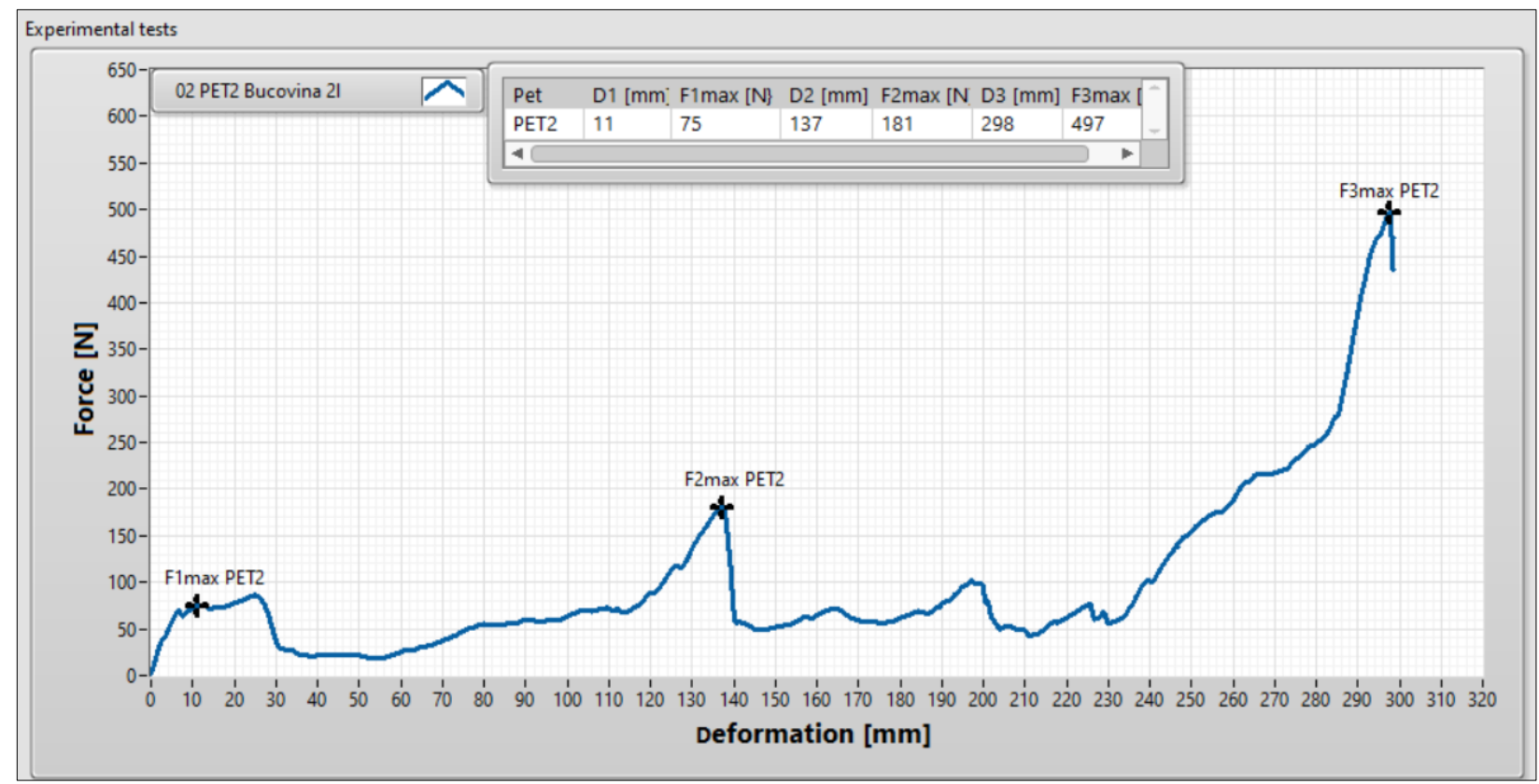

Figure 10. Diagram of force - deformation for trial PET2, 2L volume 
Values of forces $\mathrm{F} 1 \mathrm{max}=75 \mathrm{~N}, \mathrm{~F} 2 \mathrm{max}=181 \mathrm{~N}$ and $\mathrm{F} 3 \max =497 \mathrm{~N}$ indicates that active compression parts of a compactor in this case would require a force about $500 \mathrm{~N}$ for producing a compression ratio about 8. In Figure 11 it is represented the rezults from compression of 3 relevant pet bottles of L.

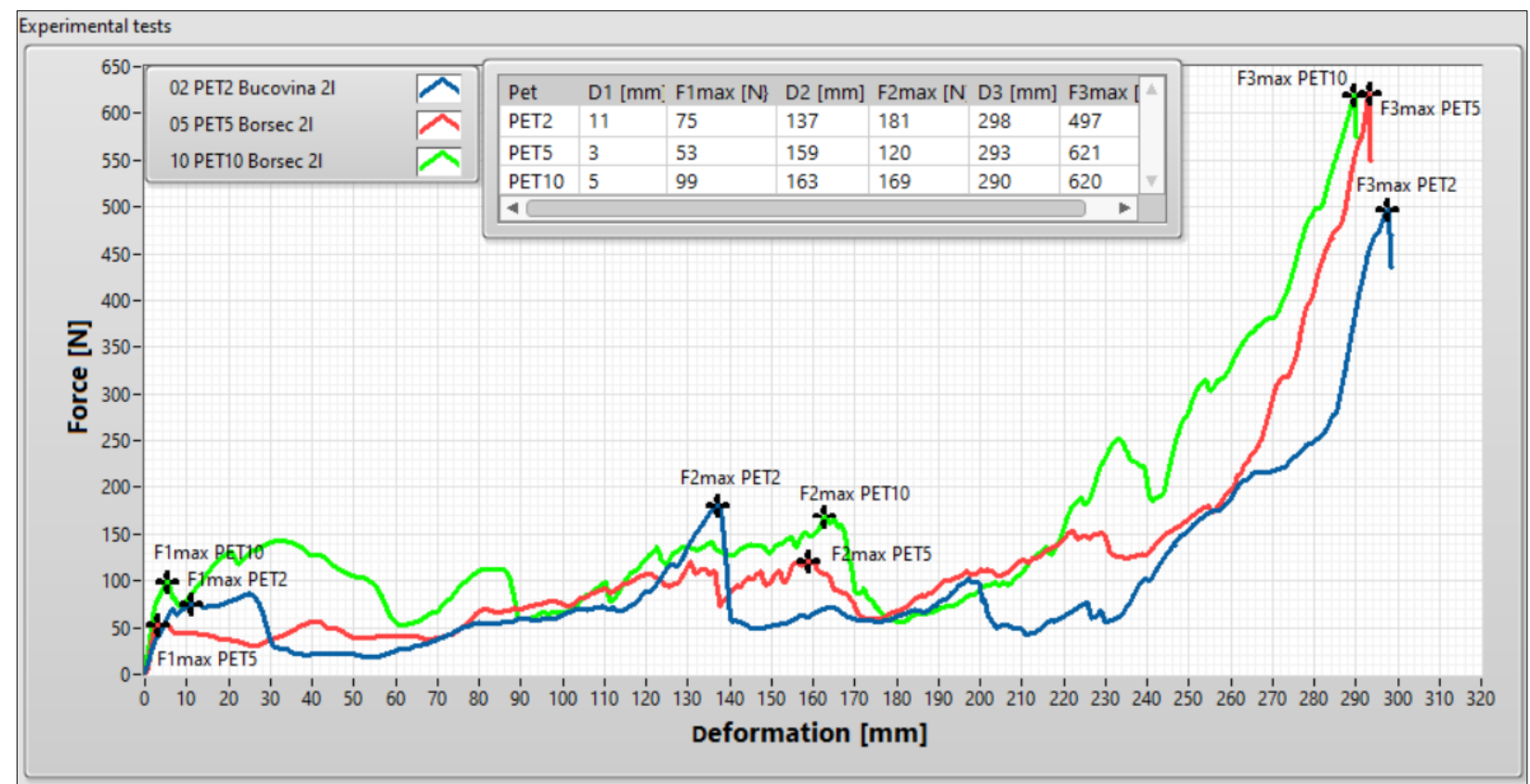

Figure 11. Diagram of force - deformation for 3 different PET bottle trials $2 \mathrm{~L}$ volume

The forces F1max were $75 \mathrm{~N}, 53 \mathrm{~N}$ and $99 \mathrm{~N}$. The F2max were $181 \mathrm{~N}, 120 \mathrm{~N}$ and $169 \mathrm{~N}$. F3max were $497 \mathrm{~N}, 621 \mathrm{~N}$ and $620 \mathrm{~N}$. This results indicates that active compression parts of a compactor in this case would require an average force about $630 \mathrm{~N}$ for producing a compression ratio about 8 .

In Figure 12 it is represented the results from compression of 2 relevant pet bottles of $0.5 \mathrm{~L}$.

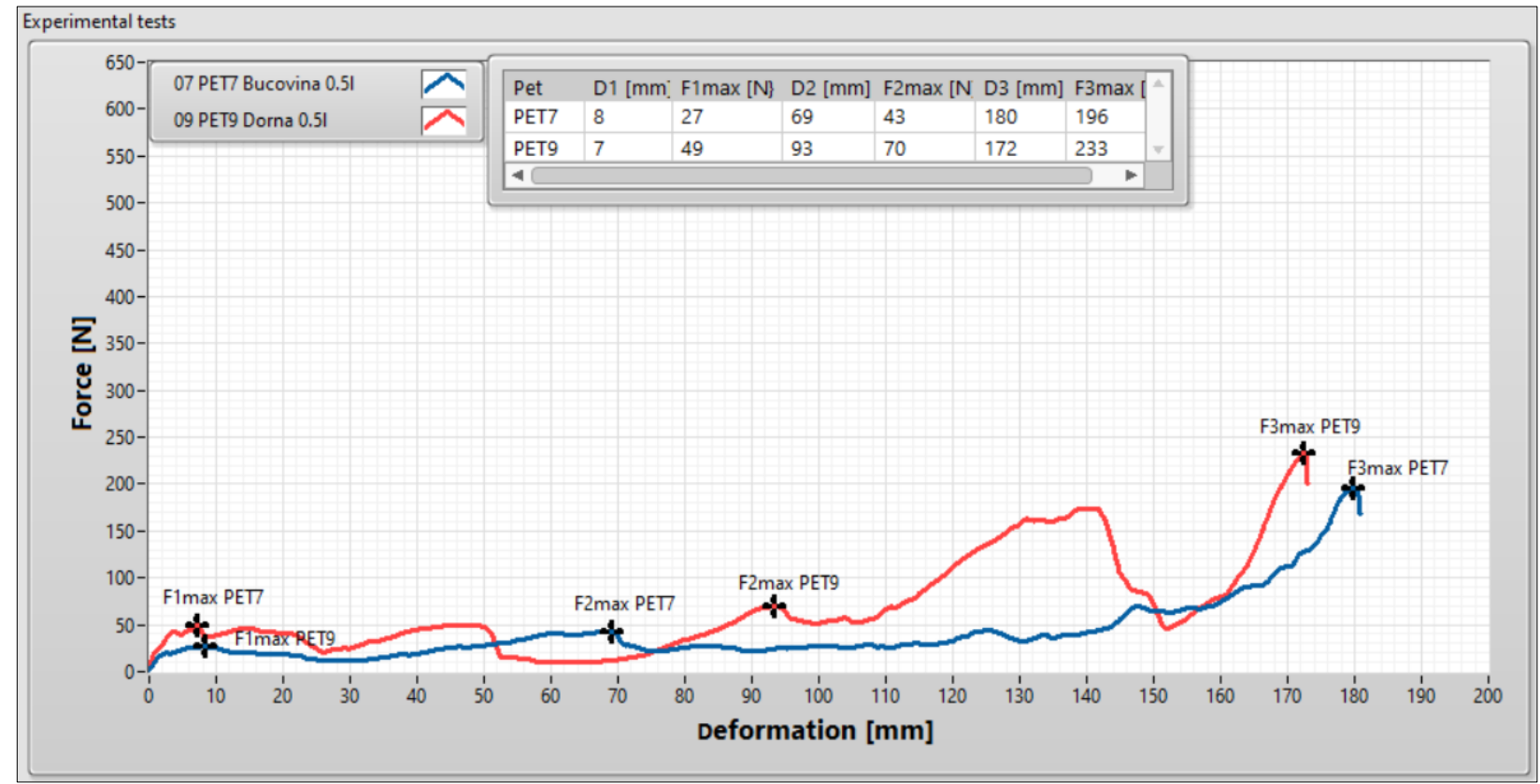

Figure 12. Diagram of force - deformation for 2 different PET bottle trials $0.5 \mathrm{~L}$ volume 
The forces F1max were $27 \mathrm{~N}$ and $49 \mathrm{~N}$. The F2max were $43 \mathrm{~N}$ and $70 \mathrm{~N}$. F3max were $196 \mathrm{~N}$ and $233 \mathrm{~N}$. This result indicates that active compression parts of a compactor in this case would require an average force about $240 \mathrm{~N}$ for producing a compression ratio about 5 .

In Figure 13 it is represented the results from compression of one relevant can of $0.33 \mathrm{~L}$.

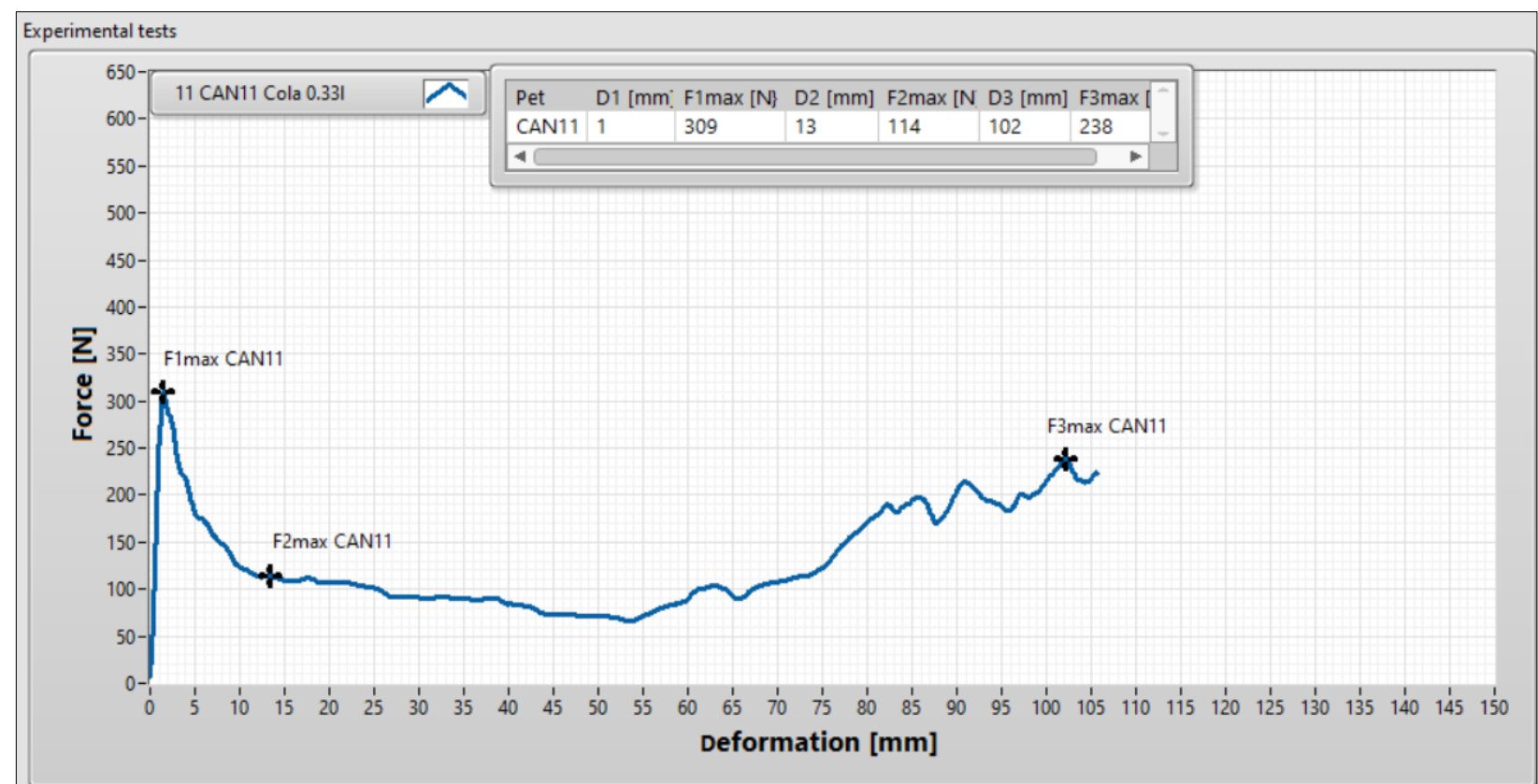

Figure 13. Diagram of force - deformation for CAN trial 0.33L volume

Values of forces F1max $=309 \mathrm{~N}, \mathrm{~F} 2 \mathrm{max}=114 \mathrm{~N}$ and $\mathrm{F} 3 \max =238 \mathrm{~N}$ indicates that active compression parts of a compactor in this case would require a force about $250 \mathrm{~N}$ for producing a compression ratio about 3.2. The remaining tests confirmed similar distribution of the forces and deformations (Figure 14).

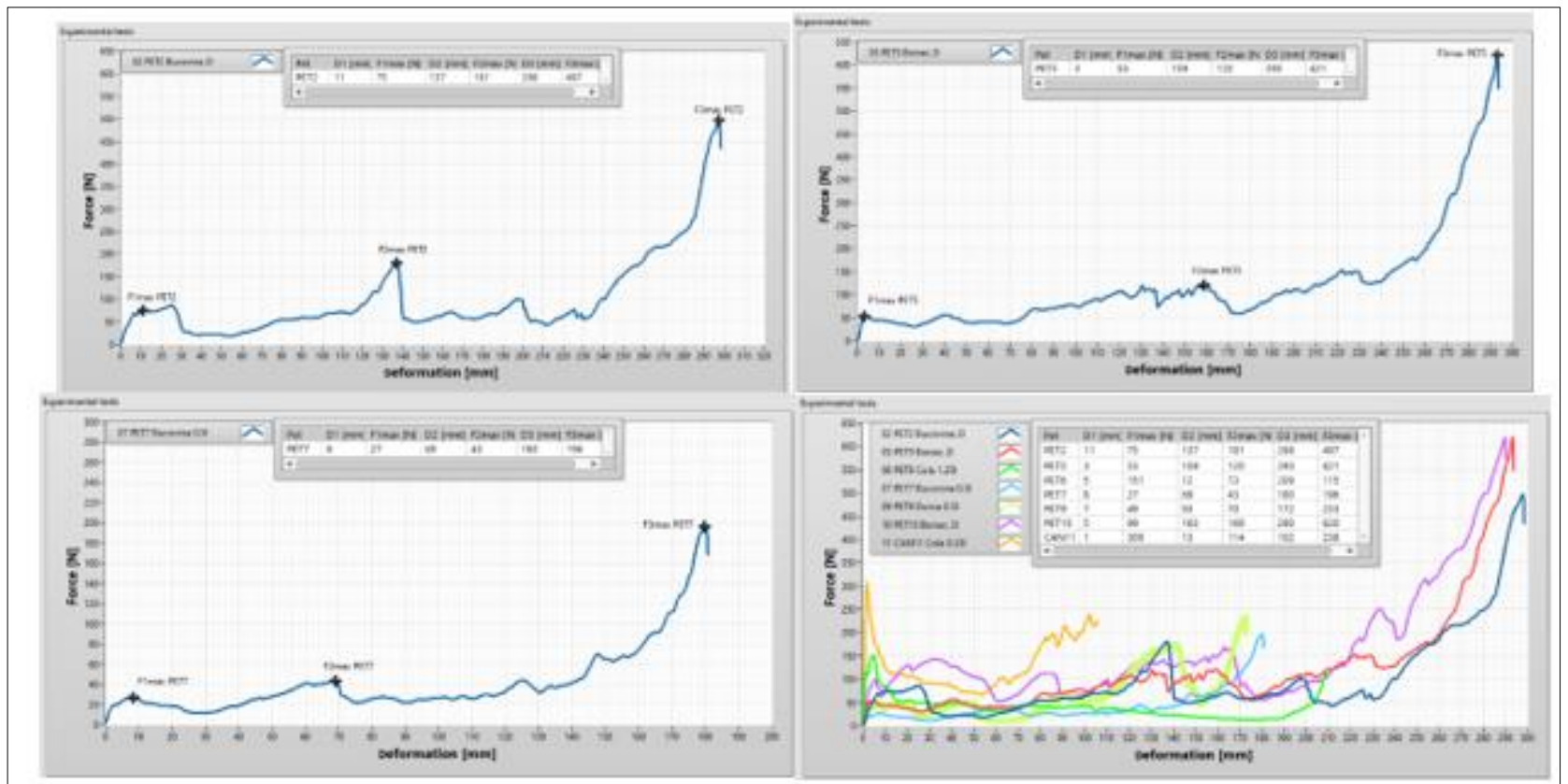

Figure 14. The other compression trials graphs

Based on these experimental trials it was confirmed the 3 stages compression behaviour for waste pet and can. It means that we can generate compression patterns with $\mathrm{F}(\mathrm{d})$ force-deformation for each 
type of waste with a specific standard volume selected. These patterns can become important inputs for conceptual design of compactor impacting concept definition of all 3 subsystems:

- Mechanical subsystem impacted parameters:

- Maximum compression force of the mechanical subsystem.

- Maximum volume compartment where the waste will be placed of the mechanical subsystem.

- Range of displacement for active compression parts to suits with most common waste volumes. It will be important to adapt deformation to each type of waste.

- Electrical subsystem impacted components:

- DC motor: No-Load Speed, Stall Torque, Stall Current.

- Driver Motor Controller: Max Continuous Current, Encoder Compatibility and Resolution.

○ Power supply.

- Software subsystem impacted State Machines programming architecture:

- Setup state machines: DEBUG_STATE state machine will need to allow importing experimental data, to allow compression patterns generation and to setup compressing parameters for working state machines for each standard waste type with a specific volume.

O Work state machines: PET_STATE and CAN_STATE should adapt in real time compressing parameters according with selected compression pattern.

- Statistics state machine: should adapt and update graphs and information based on compression patterns used.

\subsection{Development of module compression parameters from DEBUG_STATE}

For completing correlation between experimental data from compression trials and Smart Management Application Software another module was develop and integrated into main application in the frame of the DEBUG_STATE state machine. This module, called Compression Parameters, allows loading experimental data files, process them, generating graphical representation and allowing setting the maximum force for compression of the equipment (Figure 15).

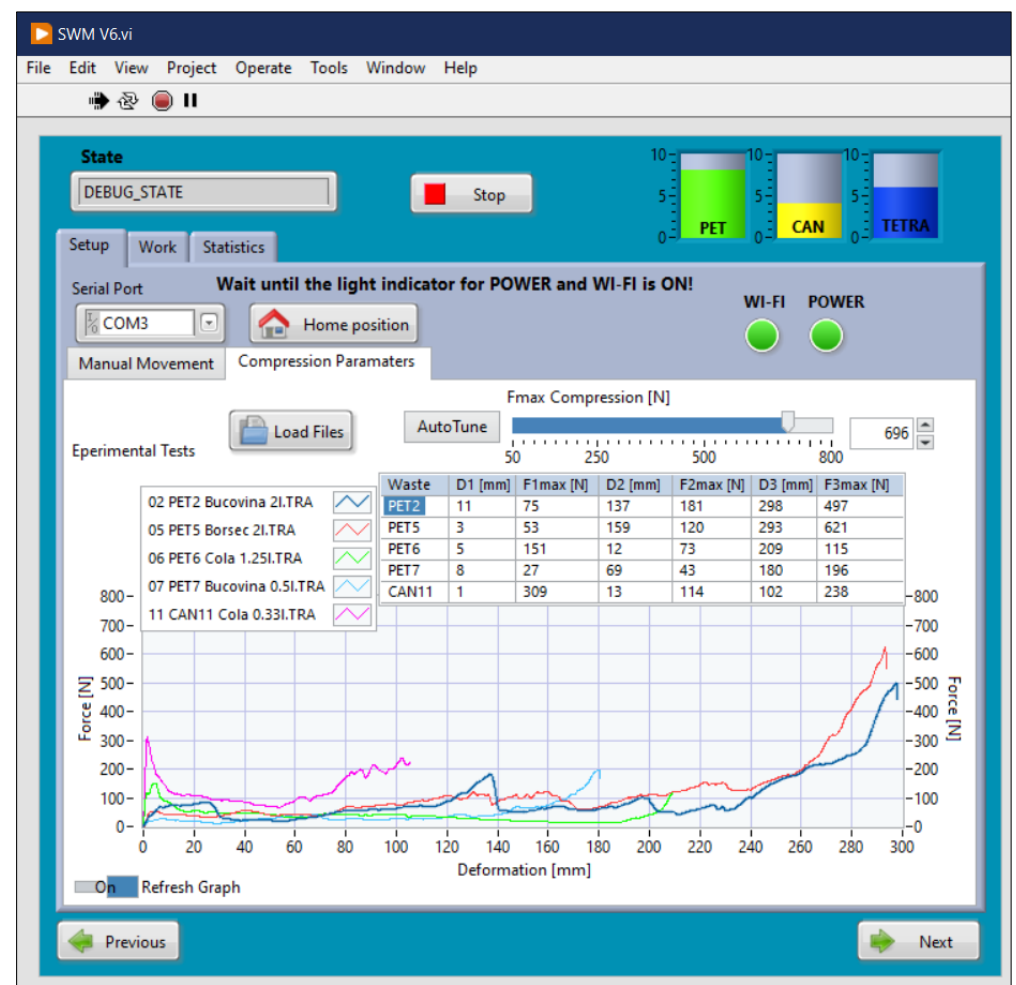

Figure 15. The front panel of module Compression Parameters from DEBUG_STATE 
Experimental data were generated by testXpert III testing software from Zwick/Roell ProLine Testing Machine in format of TRA files with specific fields: "Standard force"; "Standard travel"; "Absolute crosshead travel";"Tool separation"; "Test time"; "Time". The module Compression Parameters can import these TRA files and compute specific data of the compression process: identify the 3 compression ranges of data, calculates F1max and deformation D1, F2max and deformation D2 and F3max and deformation D3. Based on these, the maximum compression Force and deformation to be set for a specific type of waste with a standard volume can be set manually or automatically by pressing the button AutoTune. Autotuning integrates a specific proportional-integral-derivative (PID) controller algorithm which allows determining the maximum force and deformation which will be apply by the compactor during the work state machines for specific waste type with a standard volume. Autotuning algorithm should also take into account specific parameters of the mechanical and electrical subsystems.

A partial diagram with the code for module Compression Parameters is presented in Figure 16.

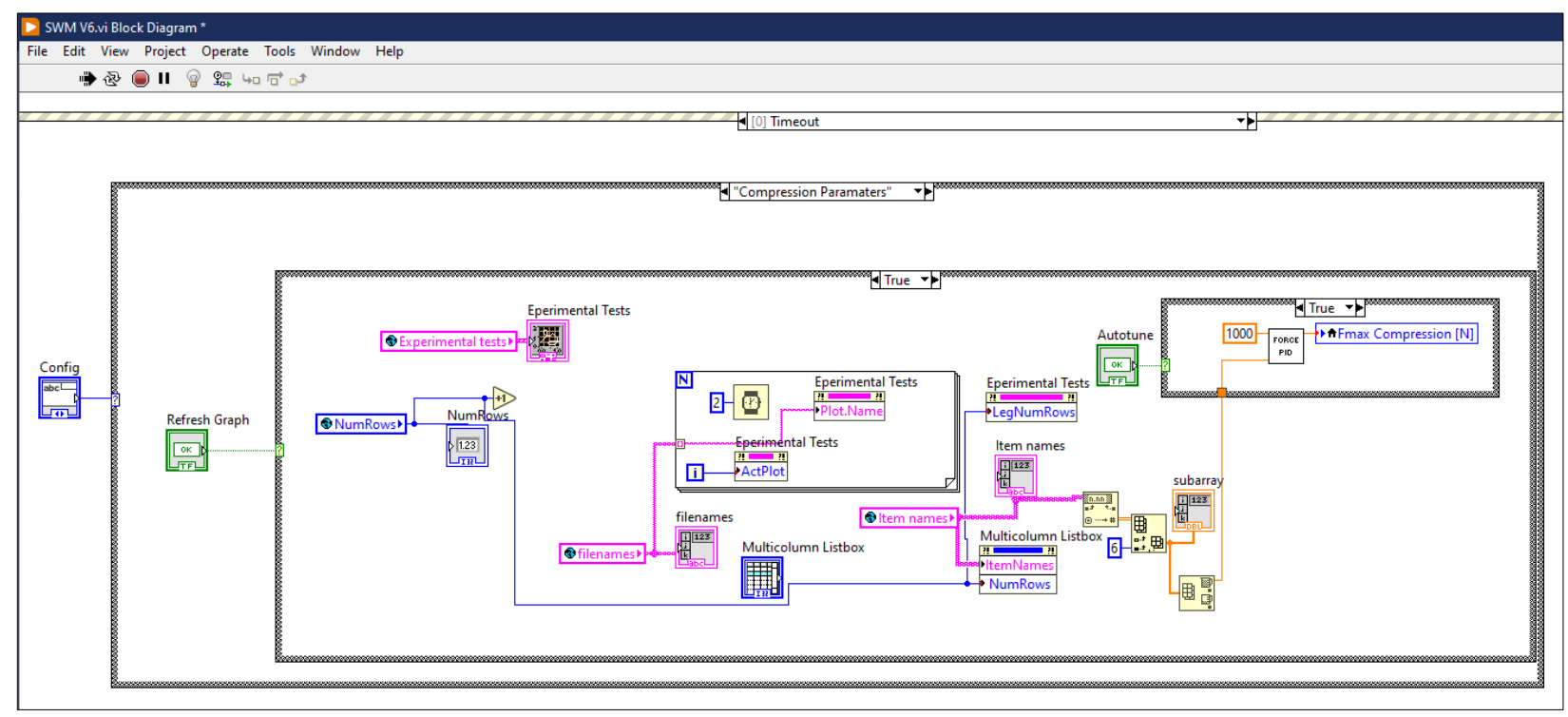

Figure 16. The block diagram of the virtual instrument for module Compression Parameters from DEBUG_STATE

Preliminary simulations and tests of the Smart Management Application Software with the new integration of the module Compression Parameters shows progress in optimization of compactor usage. There is a huge potential of development of his smart attribute (behaviour) of the waste compactor improving its adaptability to the waste type. Is also open another research development path to the predictive maintenance and continuous update of the database with compression patterns during the product usage lifecycle.

\section{Conclusions}

Development of innovative products in education at the level of master's programs focused on improving recycling process of waste can be a solid new integrative education model for developing technical and transversal competences in engineering.

In this paper it was presented an iterative product development of a model of a Waste Management System based on Industry 4.0 concepts and principles where the experimental research is linked with previous contributions of the authors related to innovative solutions for improving domestic selective waste collection.

Experimental trials performed helped in generation of compression patterns with $\mathrm{F}(\mathrm{d})$ forcedeformation for each type of waste and standard volume selected. It was confirmed a similar compression behavior with the precedent trials of waste. It was made correlation with the prototype 
compression cycle with 3 relevant stages specific to the compression of a waste. Conceptual design of compactor was impacted in concept definition of all 3 subsystems: mechanical, electrical and software.

By software development and integration of the Compression Parameters module at the level of DEBUG_STATE state machine, brought significant improvements of the software subsystem at the level of the state machines programming architecture for real time controller. This opens the door to feature developments in software optimization. Real time monitoring of compression parameters of compactor correlated with compression patterns resulted from experimental trials led to designing of a predictive and adaptive compression behaviour module. This may lead to a predictive maintenance and continuous update of the database with compression patterns during the product usage lifecycle

\section{References}

1.***How to keep a sustainable PET recycling industry in Europe. Available online: https://www.epbp.org/ (accessed on 18/06/2021)

2.ABAZA, B., JUGRAVU, B., SPANU, P., Smart Waste Management Application for Pet Bottle Compactor, Proceedings of the 36th IBIMA Conference, Granada, Spain, 4-5 November 2020

3.ABAZA, B. PARASCHIV I., SPIROIU, M. STANCIU, C. (2015), Project-based pedagogy for a new product development, 9th International Technology, Education And Development Conference, INTED 2015, 2-4th March 2015, Madrid, Spain, ISBN: 978-84-606-5763-7, ISSN 2340-1079, Published by IATED Academy, Spain 2015, pag 4348-4359.

4.SEVASTIAN, M. CERBU, R. DRAGAN, I. (2019), Studii privind dezvoltarea unui produs de compactat deşeuri reciclabile., Revista de Inginerie Industriala, Nr. 4, ISSN 2601-7938 Pag. 65-70

5.BACIU, A., M., BORDEASU, I., MICU L., M., Compressive Strength of Woven and Strand of Recycled Polyethylene Terephthalate (PET), Mater. Plast., 57(1), 2020, 263 - 271

6.KISS, I BACIU, A., M., BORDEASU, I., MICU L., M., Compressive Strength of Stripes and Flakes of Recycled Polyethylene Terephthalate (PET) Added Concrete, Mater. Plast., 57(1), 2020, 244 - 252 7.TUDOR, D. I., PETRESCU, H., HADAR, A., ROSU, A., Computer tomography investigation of defects in plastic material plates, Mater. Plast., 49(2), 2012, 123-128

Manuscript received : 21.06.2021 